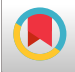

\title{
Suppressive Effect of Crocin and Cisplatin on Pluripotency Genes Expression in Human Cervical Cancer Cells \\ Homa Mollaei, ${ }^{1,2}$ Mohammad Reza Abedini, ${ }^{1}$ and Reyhane Hoshyar ${ }^{1,}{ }^{*}$
}

\author{
${ }^{1}$ Cellular and Molecular Research Center, Birjand University of Medical Sciences, Birjand, IR Iran \\ ${ }^{2}$ Department of Animal Biology, University of Tabriz, Tabriz, IR Iran \\ "Corresponding author: Reyhane Hoshyar, Cellular and Molecular Research Center, Birjand University of Medical Sciences, Birjand, IR Iran. Tel: +98-5632381542, E-mail: \\ reyhaneh.houshyar@gmail.com
}

Received 2017 February 24; Revised 2017 May 13; Accepted 2017 October 15.

\begin{abstract}
Background: Cervical cancer is the fourth most common cancer in women. Since pluripotency genes are one of the main contributors of cancer, designing novel combinational therapies that target them would be helpful.

Methods: In this study we assayed the anticancer effects of crocin and cisplatin on cervical cancer cells through suppression of Sox2 and Nanog. OV2008 cells were treated with crocin and cisplatin, and the viability and apoptosis were assessed by the MTT and Flowcytometery respectively. The expression levels of mRNA of pluripotency genes were detected by Real-Time PCR analysis.

Results: Our data showed that treatment of OV2008 cells with crocin and cisplatin decrease cell viability in a dose- and timedependent manner. Also cell cycle analysis indicated that the percentage of apoptotic cells significantly increased after treatment. Moreover, this treatment led to down-regulation of Sox 2 and Nanog genes.

Conclusions: So it would be proposed that crocin in combination with cisplatin could induce cytotoxicity in cervical cancer cells through inhibition of pluripotency genes.
\end{abstract}

Keywords: Cervical cancer, Crocin, Cisplatin, Pluripotency

\section{Background}

Cervical cancer is the fourth leading cause of cancerrelated mortality among women worldwide. Ineffectiveness of common therapeutic techniques attracts scientists' attention to combinational therapy (1). Current studies have been proved contributions of aberrant expression of stem cell marker genes, such as Sox2 and Nanog, to progression of several tumors such as esophagus (2), bladder (3), colorectal (4), lung (5), breast (6) and cervix $(7,8)$. So it is not unexpected that targeting these factors can be served as a powerful approach in cancer treatment. Cisplatin is an anti-neoplastic agent that interferes with DNA replication and kills the proliferating cells. However, because of drug resistance and unwanted side effects, combination therapies of cisplatin with other anti-tumor agents, especially herbs, have been highly suggested (9). Crocin is one of the main carotenoids of saffron (Crocus Sativus L.) that its antitumor effects have been reported on various cancer cells through interaction with multiple signaling pathways (10, 11).

\section{Objectives}

In the present study, for the first time, we aimed to evaluate the combinational effects of crocin and cisplatin on suppression of pluripotency genes, Sox2 and Nanog, in OV2008 cervical cancer cells.

\section{Methods}

Cervical cancer cell line (OV2008) was kindly provided by Doctor Benjamin K. Tsang's laboratory (University of Ottawa, Canada). The cytotoxic effects of crocin $(0-4 \mathrm{mg} / \mathrm{mL})$ and $0.003 \mathrm{mg} / \mathrm{mL}$ cisplatin measured with MTT assay. Cisplatin was obtained from Sigma (Oakville, ON, Canada) pharmaceutical company and crocin was extracted and purified according to our previous paper (12). Then OV2008 cells were treated with an effective dose of both crocin $(1.5 \mathrm{mg} / \mathrm{mL})$ and cisplatin $(0.003 \mathrm{mg} / \mathrm{mL})$ for various hours. Annexin-V-FLUOS and PI staining kit (IQProduct, Netherlands) were used for apoptosis detection. Total RNA was extracted by RNX Plus (Cinnagen, Iran) and cDNA was synthesized using Thermo-scientific Kit (USA). qRT-PCR was performed by designed primers in the ABI 
Step One ${ }^{\mathrm{TM}}$ Real-Time PCR System (Foster City, CA). The relative expression of genes was calculated by $2^{\Delta \Delta \mathrm{CT}}$ method and SYBR Green kit (Parstoos, Iran).

SOX2:AGCTACAGCATGATGCAGGA(forward), GGTCATGGAGTTGTACTGCA(reverse)

NANOG: AATACCTCAGCCTCCAGCAGATG(forward), TGCGTCACACCATTGCTATTCTTC (revers)

Bactin:

TGGCACCCAGCACAATGAA(forward),CTAAGTCATAGTCCGCCTAGAAGCA(reverse)

Results expressed as the means \pm SEM of at least three independent experiments $(n=3)$. Data were analyzed using one-way ANOVA and with Tukey's post hoc test to assess differences between experimental groups. Statistical significances inferred at $\mathrm{P} \leq 0.05$, (PRISM 6.07; Graph- Pad Software Inc.).

\section{Results}

The viability of treated cells with various concentrations of crocin $(0-4 \mathrm{mg} / \mathrm{mL})$ and $0.003 \mathrm{mg} / \mathrm{mL}$ cisplatin significantly reduced in a time- and dose-dependent manner after 24,48 and 72 hours. The $\mathrm{IC}_{50}$ values of crocin in this combinational treatment were $3,1.5$ and $1 \mathrm{mg} / \mathrm{mL}$, at 24,48 and 72 hours, respectively. Our previous study showed that $\mathrm{IC}_{50}$ values of crocin alone were higher than these doses (Under reviewed paper).

Staining of cells with Annexin V-FLOUS and PI showed that $1.5 \mathrm{mg} / \mathrm{mL}$ crocin and $0.003 \mathrm{mg} / \mathrm{mL}$ cisplatin increased early apoptosis in a time dependent manner (Figure 1). Also cell cycle analysis showed that after 24,48 , and 72 hours of treatment, the percentage of apoptotic cells in the SubG1 phase was determined as $9 \%, 10 \%$ and 33\% respectively.

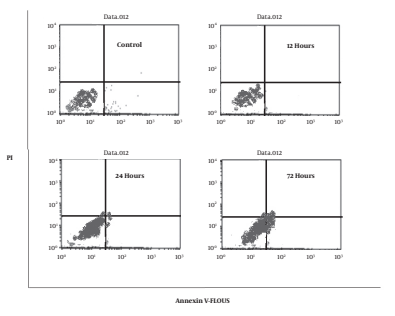

Figure 1. Effect of $1.5 \mathrm{mg} / \mathrm{mL}$ Crocin Alone (Up) and with $0.003 \mathrm{mg} / \mathrm{mL}$ Cisplatin (Down) on Apoptosis; Viable cells (Annexin V- /PI - ), early apoptotic cells (Annexin $\mathrm{V}+/ \mathrm{PI}$-), secondary necrotic cells (Annexin $\mathrm{V}+/ \mathrm{PI}+$ ), and primary necrotic cells (Annexin $\mathrm{V}$-/PI + ) are located in the lower left, lower right, upper right, and upper left quadrants, respectively.

Real-Time PCR data showed that this combinational treatment of cells led to reductions in the mRNA levels of Sox2 (Figure 2A; $\mathrm{P}<0.01, \mathrm{P}<0.0001$ ) and Nanog (Figure 2B; $\mathrm{P}<0.0001)$ at 12,24 and 36 hours. Nonetheless individual treatment of cells with $1.5 \mathrm{mg} / \mathrm{mL}$ crocin down-regulated expression levels of Sox2 (Figure $2 \mathrm{~A} ; \mathrm{P}<0.0001$ ) at all time intervals and $\mathrm{Nanog}$ (Figure $2 \mathrm{~B} ; \mathrm{P}<0.0001$ ) at just 36 hours.
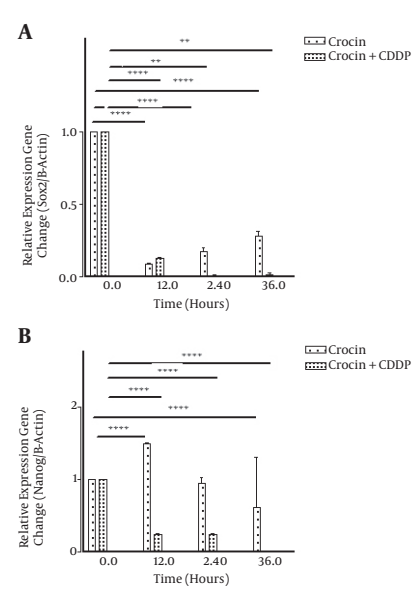

Figure 2. Effect of $1.5 \mathrm{mg} / \mathrm{mL}$ Crocin in the Present and Absent of $0.003 \mathrm{mg} / \mathrm{mL}$ CDDP on mRNA Expression of A, Sox2 and Nanog; \#Suppressive Effect of Crocin and Cisplatin on. Revision 0; Journal: Iranian Journal of Ca. Page 10 of 1124 February 2017 12:29:57; B, in OV2008 cell line.) $\left.{ }^{* *} \mathrm{P}<0.01,{ }^{* * * *} \mathrm{P}<0.0001\right)$; CDDP: Cisplatin.

\section{Discussion}

Cervical cancer is one of the main female cancers in developing countries such as Iran (13). Despite the usefulness of current therapies for this cancer, chemoresistance of tumor cells and unwanted side effects of chemical drugs remain a big challenge for oncologist (1). Several studies have proved anti-cancer properties of crocin (14-16).

In this study we investigated combinational effects of crocin and cisplatin on suppression of pluripotency genes, in cervical cancer cells. A large amount of data has showed up-regulation of key stemness factors, like Sox2 and Nanog in several types of cancer cells and the importance of targeting these regulators in cancer therapy (28). Sox 2 and Nanog are transcription factors that are essential for maintaining self-renewal or pluripotency of undifferentiated embryonic stem cells (17). Up-regulation of these factors and disregulation of downstream regulatory pathways affects several aspects of cancer development such as cell proliferation, self-renewal, motility, epithelialmesenchymal transition, and drug-resistance (18). The effects of Cisplatin as a chemotherapy drug on pluripotency genes have been evaluated before $(19,20)$. So finding the novel agents in combination with this drug as pluripotency regulators could help us to improve efficiency of cancer therapy. In the present study we aimed to investigate the molecular mechanism of crocin via alternation of 
ploripotency genes. Our result showed that treatment of cervical cancer cells with crocin and cisplatin could reduce the expression level of Sox 2 and Nanog and also increase the percentage of apoptotic cells and cytotoxicity of cisplatin in these cells. Also according to our previous study, we could claim that combinational treatment of crocin and cisplatin is more effective than each of them individually. In conclusion, it could be proposed that crocin might serve as an adjuvant therapy for cervical cancer besides cisplatin.

\section{Acknowledgments}

None declared.

\section{Footnotes}

Authors' Contribution: Reyhane Hoshyar designed the study, and revised the paper. Mohammad Reza Abedini designed the study, Homa Mollaei performed all tests and written the paper.

Conflict of Interests: None declared.

Financial Discloser: None declared.

\section{References}

1. Obstetricians ACo Gynecologists. Diagnosis and treatment of cervical carcinomas. Washington (DC): American College of Obstetricians and Gynecologists (ACOG);2002.

2. He W, Li K, Wang F, Qin YR, Fan QX. Expression of OCT4 in human esophageal squamous cell carcinoma is significantly associated with poorer prognosis. World J Gastroenterol. 2012;18(7):712-9. doi: 10.3748/wjg.v18.i7.712. [PubMed: 22363145].

3. Tahmasebi MM, Sadeghizadeh M, Najafi F, Mowla SJ. Dendrosomal curcumin induced apoptosis by suppression of pluripotency genes in 5637 bladder cancer cells. Modares J Med Sci Pathobiol. 2013;16(1):2339.

4. Gazouli M, Roubelakis MG, Theodoropoulos GE, Papailiou J, Vaiopoulou A, Pappa KI, et al. OCT4 spliced variant OCT4B1 is expressed in human colorectal cancer. Mol Carcinog. 2012;51(2):165-73. doi: 10.1002/mc.20773. [PubMed: 21480394].

5. Karoubi G, Gugger M, Schmid R, Dutly A. OCT4 expression in human non-small cell lung cancer: implications for therapeutic intervention. Interact Cardiovasc Thorac Surg. 2009;8(4):393-7. doi: 10.1510/icvts.2008.193995. [PubMed:19126554].

6. Leis O, Eguiara A, Lopez-Arribillaga E, Alberdi MJ, Hernandez-Garcia $\mathrm{S}$, Elorriaga $\mathrm{K}$, et al. Sox 2 expression in breast tumours and activation in breast cancer stem cells. Oncogene. 2012;31(11):1354-65. doi: 10.1038/onc.2011.338. [PubMed: 21822303].
7. Vishnoi K, Tyagi A, Singh SM, Das BC, Bharti AC. . Springer; 2015. Cervical Cancer Stem Cells and Their Association with Human Papillomavirus: Are They Ready as Anticancer Targets?Multi-Targeted Approach to Treatment of Cancer; p. 377-99.

8. Liu XF, Yang WT, Xu R, Liu JT, Zheng PS. Cervical cancer cells with positive Sox2 expression exhibit the properties of cancer stem cells. PLoS One. 2014;9(1). e87092. doi: 10.1371/journal.pone.0087092. [PubMed: 24489842].

9. Zhu H, Luo H, Zhang W, Shen Z, Hu X, Zhu X. Molecular mechanisms of cisplatin resistance in cervical cancer. Drug Des Devel Ther. 2016;10:1885-95. doi: 10.2147/DDDT.S106412. [PubMed: 27354763].

10. Mostafavinia SE, Khorashadizadeh M, Hoshyar R. Antiproliferative and Proapoptotic Effects of Crocin Combined with Hyperthermia on Human Breast Cancer Cells. DNA Cell Biol. 2016;35(7):340-7. doi: 10.1089/dna.2015.3208. [PubMed: 27003728].

11. Hoshyar R, Bathaie SZ, Sadeghizadeh M. Crocin triggers the apoptosis through increasing the Bax/Bcl-2 ratio and caspase activation in human gastric adenocarcinoma, AGS, cells. DNA Cell Biol. 2013;32(2):50-7. doi: 10.1089/dna.2012.1866. [PubMed: 23347444].

12. Bolhasani A, Bathaie SZ, Yavari I, Moosavi-Movahedi AA, Ghaffari M. Separation and purification of some components of Iranian saffron. Asian J Chem. 2005;17(2):725.

13. Behtash N, Karimi Zarchi M, Deldar M. Preoperative prognostic factors and effects of adjuvant therapy on outcomes of early stage cervical cancer in Iran. Asian Pac J Cancer Prev. 2009;10(4):613-8. [PubMed: 19827880].

14. Hoshyar R, Mostafavinia SE, Bathaie SZ. Anticancer effects of saffron stigma (Crocus Sativus): a review study. Razi JMed Sci. 2016;22(140):6978.

15. Abdullaev FI, Espinosa-Aguirre JJ. Biomedical properties of saffron and its potential use in cancer therapy and chemoprevention trials. Cancer Detect Prev. 2004;28(6):426-32. doi: 10.1016/j.cdp.2004.09.002. [PubMed: 15582266].

16. Alavizadeh $\mathrm{SH}$, Hosseinzadeh $\mathrm{H}$. Bioactivity assessment and toxicity of crocin: a comprehensive review. Food Chem Toxicol. 2014;64:65-80. doi: 10.1016/j.fct.2013.11.016. [PubMed: 24275090].

17. Jeter CR, Yang T, Wang J, Chao HP, Tang DG. Concise Review: NANOG in Cancer Stem Cells and Tumor Development: An Update and Outstanding Questions. Stem Cells. 2015;33(8):2381-90. doi: 10.1002/stem.2007. [PubMed: 25821200].

18. Wang ML, Chiou SH, Wu CW. Targeting cancer stem cells: emerging role of Nanog transcription factor. Onco Targets Ther. 2013;6:1207-20. doi: 10.2147/OTT.S38114. [PubMed: 24043946].

19. Abedini MR, Muller EJ, Brun J, Bergeron R, Gray DA, Tsang BK. Cisplatin induces p53-dependent FLICE-like inhibitory protein ubiquitination in ovarian cancer cells. Cancer Res. 2008;68(12):4511-7. doi: 10.1158/0008-5472.CAN-08-0673. [PubMed: 18559494].

20. Barr MP, Gray SG, Hoffmann AC, Hilger RA, Thomale J, O'Flaherty JD, et al. Generation and characterisation of cisplatin-resistant nonsmall cell lung cancer cell lines displaying a stem-like signature. PLoS One. 2013;8(1). e54193. doi: 10.1371/journal.pone.0054193. [PubMed: 23349823]. 